\title{
Cohnella thermotolerans gen. nov., sp. nov., and classification of 'Paenibacillus hongkongensis' as Cohnella hongkongensis sp. nov.
}

\author{
Correspondence \\ Peter Kämpfer \\ peter.kaempfer@agrar. \\ uni-giessen.de
}

\author{
Peter Kämpfer, ${ }^{1}$ Ramon Rosselló-Mora, ${ }^{2}$ Enevold Falsen, ${ }^{3}$ \\ Hans-Jürgen Busse ${ }^{4}$ and Brian J. Tindall ${ }^{5}$ \\ ${ }^{1}$ Institut für Angewandte Mikrobiologie, Justus-Liebig Universität Giessen, \\ IFZ-Heinrich-Buff-Ring 26-32, D-35392 Giessen, Germany \\ ${ }^{2}$ Grup d'Oceanografia Interdisciplinari, Institut Mediterrani d'Estudis Avançats (CSIC-UIB), \\ Esporles, Mallorca, Spain \\ ${ }^{3}$ CCUG, Culture Collection University of Göteborg, Göteborg, Sweden \\ ${ }^{4}$ Institut für Bakteriologie, Mykologie und Hygiene, Veterinärmedizinische Universität, Wien, \\ Austria \\ ${ }^{5}$ DSMZ, Mascheroder Weg 1b, D-38240 Braunschweig, Germany
}

The genus Paenibacillus was originally proposed by Ash et al. $(1993,1994)$ for rRNA group 3 bacilli, mainly on the basis of $16 \mathrm{~S}$ rRNA gene sequence data and the fact that this group was distinct from other groups which they defined within the bacilli. The genus description was emended by Shida et al. (1997) and, to date, the genus comprises more than 60 species, most of which were listed by Aguilera et al. (2001), Berge et al. (2002), Bosshard et al. (2002), Elo et al. (2001), Genersch et al. (2006), Iida et al. (2005), Kim et al. (2004),

The GenBank/EMBL/DDBJ accession number for the 16S rRNA gene sequence of CCUG $47242^{\top}$ is AJ971483.

Phylogenetic trees constructed using the neighbour-joining and maximum-parsimony methods are available as supplementary figures in IJSEM Online.
Meehan et al. (2001), Montes et al. (2004), Rivas et al. (2005a, b), Rodríguez-Díaz et al. (2005), Saha et al. (2005), Sánchez et al. (2005), Šmerda et al. (2005), Takeda et al. (2005), von der Weid et al. (2002) and Yoon et al. (2003, 2005). The taxonomic dissection of the genus Bacillus (initiated by Ash et al., 1991), based largely on a 16S rRNA gene sequence perspective, has been summarized by Stackebrandt \& Swiderski (2002).

Strain CCUG $47242^{\mathrm{T}}$ was isolated on blood agar at $37^{\circ} \mathrm{C}$ during hygiene control checks at a starch-producing company in Sweden. Subcultivation was done on tryptone soy agar (TS agar; Oxoid) at $30^{\circ} \mathrm{C}$ for $24 \mathrm{~h}$. On this agar, strain CCUG $47242^{\mathrm{T}}$ was able to grow at $20-55^{\circ} \mathrm{C}$, but not at 10 or $60{ }^{\circ} \mathrm{C}$. Growth at $30^{\circ} \mathrm{C}$ was also observed on nutrient agar and R2A agar, but not on Salmonella-Shigella agar (SS agar; 

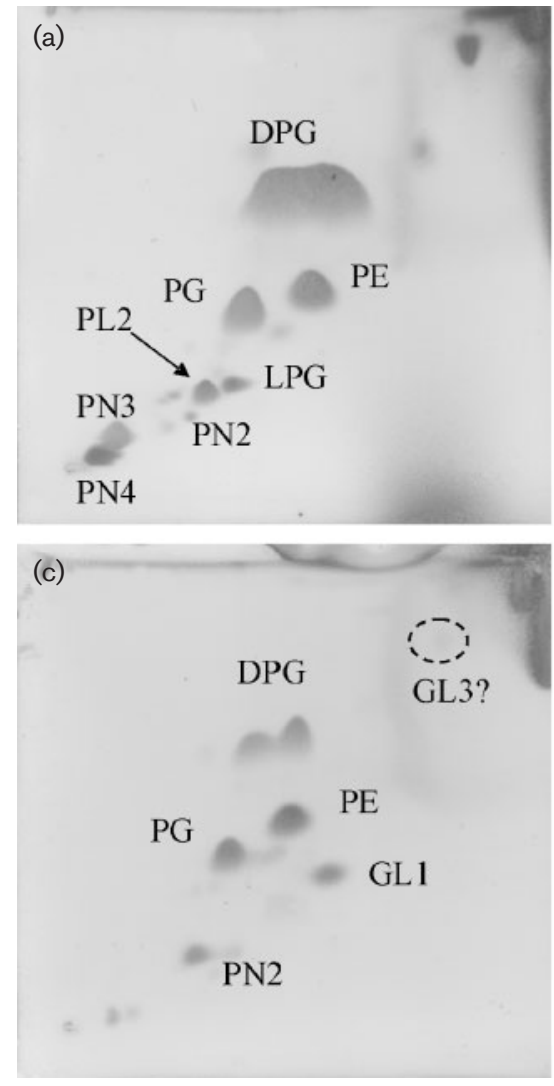
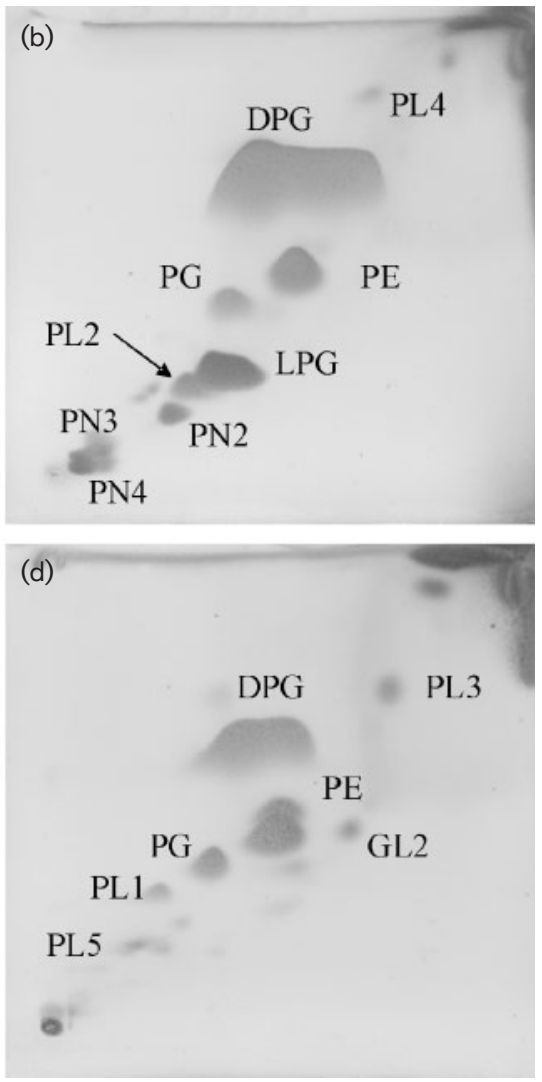

Fig. 1. Polar lipid profiles after separation by two-dimensional thin layer chromatography. (a) Strain CCUG 47242'; (b) HKU3; (c) Bacillus subtilis DSM $10^{\mathrm{T}}$; (d) Paenibacillus polymyxa DSM $36^{\top}$. DPG, Diphosphatidylglycerol; PG, phosphatidylglycerol; PE, phosphatidylethanolamine; PL1-5, unknown phospholipids; LPG, lysyl-phosphatidylglycerol; PN2-4, unknown aminophospholipids; GL1, $\beta$-gentiobiosyldiacylglycerol; GL2 and GL3, unknown glycolipids. all media from Oxoid). Gram-staining was performed as described by Gerhardt et al. (1994). Cell morphology was observed under a Zeiss light microscope at $\times 1000$, using cells that had been grown for $24 \mathrm{~h}$ at $30^{\circ} \mathrm{C}$ on TS agar. Details of cell morphology are given in the species description. The 16S rRNA gene sequence was analysed as described previously (Kämpfer et al., 2003). Analysis of the sequence data was performed by using MEGA version 2.1 (Kumar et al., 2001), after multiple alignment of sequences by CLUSTAL_X (Thompson et al., 1997). A distance-matrix method (distance options according to the Kimura two-parameter model) that used clustering with the neighbour-joining method (see Supplementary Fig. S1 in IJSEM Online), as well as a discrete character-based maximum-parsimony method (Supplementary Fig. S2 in IJSEM Online), were performed. In each case, bootstrap values were calculated based on 1000 replications. The $16 \mathrm{~S}$ rRNA gene sequence of strain CCUG $47242^{\mathrm{T}}$ was a continuous stretch of $1486 \mathrm{bp}$. Sequence similarity calculations indicated that strain CCUG $47242^{\mathrm{T}}$ showed the greatest degree of similarity to 'Paenibacillus hongkongensis' HKU3 (GenBank accession no. AF433165; $96.58 \%$ ), which was described by Teng et al. (2003) (this name has not been validly published to date). Significantly lower sequence similarities $(<94.5 \%)$ were found with all other recognized species of the genus Paenibacillus.

Chemotaxonomic analyses were performed as follows: respiratory quinones (Tindall, 1990), polar lipids (Tindall, 1990) and fatty acids (Kämpfer \& Kroppenstedt, 1996).
Although respiratory quinones have low resolution within the bacilli, the presence of MK-7 supports the affiliation of strains CCUG $47242^{\mathrm{T}}$ and HKU3 to the genus Paenibacillus, where all species investigated to date have MK-7 as the major quinone. MK-7 represented $98 \%$ of the quinones of strains CCUG $47242^{\mathrm{T}}$ and HKU3; in addition, small amounts of MK-6 (1\%) and MK-8 (1\%) were detected.

Strains CCUG $47242^{\mathrm{T}}$ and HKU3 displayed a complex polar lipid profile, which consisted of diphosphatidylglycerol, phosphatidylglycerol, phosphatidylethanolamine, lysylphosphatidylglycerol, two unknown phospholipids and four unknown aminophospholipids (Fig. 1).

The fatty acid profiles of strains CCUG $47242^{\mathrm{T}}$ and HKU3 (given in the species description) were similar to those of other Paenibacillus species; however, it was striking that the amounts of iso-C16:0 (45.5\% for strain CCUG $\left.47242^{\mathrm{T}}\right)$ or C16: 0 (25.3\% for strain HKU3) were very large. Such large amounts of iso-C16:0 have not been reported for Paenibacillus species before. Members of the genus Thermobacillus, described by Touzel et al. (2000), showed a similar fatty acid content to strain CCUG $47242^{\mathrm{T}}$ with respect to C16: 0 and C17:0, but not for the other fatty acids. Kämpfer (2002) compiled fatty acid data for paenibacilli and found that the major fatty acids of the genus Paenibacillus (with ranges as percentages of total given in parentheses) are anteiso-C15 : 0 (36-80\%), iso-C16:0 (0.5-6\%), iso-C15 : 0 $(1-12 \%)$ and anteiso-C17:0 (6.7\%). 
Although some progress has been made in the reclassification of the bacilli, there is still some question as to what constitutes the genus Bacillus and whether other genera created over the years should be split further or combined with other genera. Redefining the genus Bacillus or the genus Paenibacillus would need extensive comparative work that would at present hinder the creation of novel taxa that may be closely associated with the genera Bacillus or Paenibacillus. This problem is clearly evident in a recent publication by Heyrman et al. (2005), where novel species within Bacillus group 2 are, by default, also placed in the genus Bacillus, although this group also contains members of the genera Kurthia, Caryophanon and Sporosarcina. The alternative is to define clearly the properties of the type species of the genera Bacillus and Paenibacillus and to create novel genera where clear differences can be found without having first to wait for extensive taxonomic rearrangements. This approach can be most effectively undertaken using a combination of $16 \mathrm{~S}$ rRNA gene sequence data and chemical composition analysis. Such an approach leads to a rather different perspective of the potential taxonomic groupings than that based on $16 \mathrm{~S}$ rRNA gene sequence data alone. It should be noted that features such as physiology, biochemistry and morphology may also be correlated with these data and all such data should be used to evaluate the taxonomic significance once groupings have been established. A clear distinction has to be made between groupings and genera. In the future, this may be expanded to include more detailed information from total genome analysis, although it is essential that such information should be coupled to other aspects such as biochemical pathways and structural proteins etc. (i.e. the epigenetic level).

It is well documented that the chemical composition of members of the bacilli is heterogeneous (Minnikin \& Goodfellow, 1981; O'Leary \& Wilkinson, 1988). However, in recent years, much emphasis has been put on the use of fatty acids. While some differentiation is possible, they appear to be of limited value in further differentiating within the bacilli. In the case of respiratory lipoquinones, menaquinones dominate, with isoprenoid chain lengths from 6 to 9 . The most commonly encountered menaquinone is MK-7. Closer examination of polar lipids indicates a greater degree of variation, although this method has not been widely applied in recent years. In the case of members of Bacillus group 1 (Ash et al., 1991), there is chemical heterogeneity within the group (Minnikin \& Goodfellow, 1981; O'Leary \& Wilkinson, 1988). However, Bacillus subtilis, the type species of the genus Bacillus, produces diphosphatidylglycerol, phosphatidylglycerol, diphosphatidylethanolamine, an aminoacylphosphatidylglycerol and a glycolipid, which has been identified as a $\beta$-gentiobiosyldiacylglycerol (Minnikin \& Goodfellow, 1981). Species sharing this polar lipid pattern, together with MK-7 and the fatty acid pattern listed in Table 1, should, in the future, constitute the 'core' of the genus Bacillus. The polar lipid composition of the type species of the genus Paenibacillus, Paenibacillus polymyxa, is different. The single glycolipid present does not have the
Table 1. Fatty acid content (\%) of Bacillus subtilis, Paenibacillus polymyxa, Cohnella thermotolerans CCUG $47242^{\top}$ and Cohnella hongkongensis $\mathrm{HKU}^{\mathrm{T}}$

The data for B. subtilis and P. polymyxa are taken from Kämpfer (2002) and were compiled from several species descriptions. 1, B. subtilis; 2, P. polymyxa; 3, C. thermotolerans CCUG $47242^{\mathrm{T}} ; 4$, C. hongkongensis $\mathrm{HKU}^{\mathrm{T}}$.

\begin{tabular}{|c|c|c|c|c|}
\hline Fatty acid & 1 & 2 & 3 & 4 \\
\hline ai-13:0 & & & & $0 \cdot 8$ \\
\hline i-14:0 & 1 & & $2 \cdot 1$ & $2 \cdot 3$ \\
\hline $14: 0$ & & & 1 & 5 \\
\hline i- $15: 0$ & 27 & 1 & $3 \cdot 2$ & $8 \cdot 1$ \\
\hline ai-15:0 & 39 & 63 & $28 \cdot 4$ & $31 \cdot 2$ \\
\hline $15: 0$ & & & $1 \cdot 4$ & 8 \\
\hline i- $16: 0$ & 1 & 6 & $45 \cdot 5$ & $11 \cdot 9$ \\
\hline $\mathrm{i}-16: 1$ & 1 & & & \\
\hline $16: 0$ & 1 & 9 & $6 \cdot 6$ & $25 \cdot 3$ \\
\hline $16: 1 \omega 11 c$ & & & & $0 \cdot 9$ \\
\hline $\mathrm{i}-17: 0$ & 8 & 2 & & \\
\hline ai-17:0 & 1 & 17 & $6 \cdot 7$ & $2 \cdot 6$ \\
\hline $\mathrm{i}-17: 1$ & 3 & & $1 \cdot 1$ & 1.9 \\
\hline $17: 0$ & & & & $1 \cdot 2$ \\
\hline ai-17: 1 & 10 & & & \\
\hline $17: 1 \omega 6 c$ & & & 1 & \\
\hline Other & 8 & & & \\
\hline $18: 1 \omega 7 c$ & & & 4 & \\
\hline
\end{tabular}

same $R_{\mathrm{f}}$ value as $\beta$-gentiobiosyldiacylglycerol. While the major phospholipids present are diphosphatidylglycerol, phosphatidylglycerol and diphosphatidylethanolamine, they only serve (together with the presence of menaquinones and iso/ anteiso fatty acids) to confirm that this species belongs to the bacilli. The presence of a number of unidentified phospholipids serves to differentiate this species. Preliminary work on the polar lipid composition of the genus Paenibacillus indicates that this group is also heterogeneous (S. Kirschner and B. J. Tindall, unpublished; Minnikin \& Goodfellow, 1981; O'Leary \& Wilkinson, 1988); only those species sharing a similar chemical composition to the type species should be retained in the genus Paenibacillus in the future.

In the case of the two strains studied here, their chemical composition also centres around the presence of menaquinones (MK-7), the dominance of iso and anteiso fatty acids, together with diphosphatidylglycerol, phosphatidylglycerol and diphosphatidylethanolamine as the predominant phospholipids. However, among the polar lipids, the two strains share the same property of having a number of phospholipids and aminophospholipids that are not present in the type species of the genera Bacillus and Paenibacillus.

In particular, the lipid labelled LPG had the same $R_{\mathrm{f}}$ value as authentic lysyl-phosphatidylglycerol, which has been identified in Staphylococcus (Nahaie et al., 1984) and Listeria (Fischer \& Leopold, 1999) species. The biosynthesis of this lipid is unusual in that lysine tRNA serves as the source of 
lysine (Gould \& Lennarz, 1967, 1970; Lennarz et al., 1966). A specific enzyme has been identified that is responsible for the incorporation of lysine into the parent phospholipids (Oku et al., 2004). This lipid, and other amino acid derivatives of phospholipids, have also been found in other bacilli (Minnikin \& Goodfellow, 1981; O’Leary \& Wilkinson, 1988), as well as in members of the genera Enterococcus, Lactobacillus, Listeria, Vagococcus and Staphylococcus (Fischer \& Leopold, 1999; Fischer \& Arneth-Seifert, 1998; Nahaie et al., 1984; O'Leary \& Wilkinson, 1988). The ability to synthesize such lipids (including other amino acid derivatives) must also be seen in a taxonomic and evolutionary context, being particularly prevalent in this branch of the Gram-positive bacteria. This study, and previous work, clearly indicates the value of chemotaxonomy within the bacilli and further supports the need for the inclusion of such analyses in all future taxonomic work on this group. This is also consistent with the often forgotten remarks of the ad hoc committee (Wayne et al., 1987), which emphasized the need to carry out more chemotaxonomic work.

The results of physiological characterization, using methods that have been described previously (Kämpfer et al., 1991), are given in the species descriptions. Strain CCUG $47242^{\mathrm{T}}$ was able to utilize many carbohydrates, but organic acids and amino acids were not utilized. In the case of HKU3, no positive results for carbon source utilization tests were reported (Teng et al., 2003). On the basis of the results presented, we propose that strains CCUG $47242^{\mathrm{T}}$ and HKU3 represent separate novel species of a new genus, Cohnella gen. nov.

\section{Description of Cohnella gen. nov.}

Cohnella (Coh.nel'la. N.L. fem. dim. n. Cohnella named after Ferdinand Cohn, the German microbiologist who first described the bacterial genus Bacillus in 1872).

Cells are Gram-positive, spore-forming, aerobic, non-motile, rod-shaped and thermotolerant. Good growth occurs after $24 \mathrm{~h}$ incubation on TS and nutrient agars at $25-30^{\circ} \mathrm{C}$; good growth also occurs at $55^{\circ} \mathrm{C}$. Main menaquinone is MK-7. Predominant polar lipids are diphosphatidylglycerol, phosphatidyglycerol, phosphatidylethanolamine and lysylphosphatidylglycerol. In addition, two unknown phospholipids and four unknown aminophospholipids are present. The major fatty acids are iso C16:0, anteiso C15:0 and C16:0. The type species is Cohnella thermotolerans.

\section{Description of Cohnella thermotolerans sp. nov.}

Cohnella thermotolerans (ther.mo.tol'er.ans. Gr. n. therme heat; L. pres. part. tolerans tolerating; N.L. part. adj. thermotolerans able to tolerate high temperatures).

Displays the following properties in addition to those given in the genus description. Oxidase-positive and shows an oxidative metabolism. The fatty acid profile of the type strain comprises iso C16:0 (45.5\%), anteiso C15:0 $(28 \cdot 4 \%)$, anteiso C17:0 (6.7\%), C16:0 (6.6\%),
$\mathrm{C} 18: 1 \omega 7 c(4 \cdot 0 \%)$, iso $\mathrm{C} 15: 0(3 \cdot 2 \%)$, iso $\mathrm{C} 14: 0(2 \cdot 1 \%)$, $\mathrm{C} 15: 0(1 \cdot 4 \%)$, iso $\mathrm{C} 17: 0(1 \cdot 1 \%), \mathrm{C} 14: 0(1 \cdot 0 \%)$ and $\mathrm{C} 17: 1 \omega 6 c(1 \cdot 0 \%)$. Aesculin and p-nitrophenol (pNP) $\beta$ D-glucopyranoside are hydrolysed. Arbutin, L-arabinose (weakly), D-cellobiose, D-fructose, D-galactose, gluconate, D-glucose, D-maltose, D-mannose, $\alpha$-D-melibiose, L-rhamnose (weakly) and D-ribose are utilized as sole sources of carbon. No acid production from glucose, lactose, sucrose, D-mannitol, dulcitol, salicin, adonitol, inositol, sorbitol, L-arabinose, raffinose, rhamnose, maltose, D-xylose, trehalose, cellobiose, methyl D-glucoside, erythritol, melibiose, $\mathrm{D}$-arabitol or D-mannose. No hydrolysis of o-NP $\beta$-Dgalactopyranoside, $\mathrm{pNP} \beta$-D-glucuronide, $\mathrm{pNP} \alpha$-D-glucopyranoside, pNP $\beta$-D-xylopyranoside, bis-pNP phosphate, pNP phenylphosphonate, pNP phosphorylcholine, 2-deoxythymidine-5'-pNP phosphate, L-alanine p-nitroanilide (pNA), L-glutamate- $\gamma$-3-carboxy pNA or L-proline pNA. The following carbon sources are not utilized: $N$-acetyl-Dgalactosamine, $N$-acetyl-D-glucosamine, sucrose, salicin, D-trehalose, D-xylose, adonitol, i-inositol, maltitol, Dmannitol, D-sorbitol, putrescine, acetate, propionate, cis-aconitate, trans-aconitate, adipate, 4-aminobutyrate, azelate, citrate, fumarate, glutarate, DL-3-hydroxybutyrate, itaconate, DL-lactate, L-malate, mesaconate, oxoglutarate, pyruvate, suberate, $\mathrm{L}$-alanine, $\beta$-alanine, $\mathrm{L}$-aspartate, $\mathrm{L}$-histidine, L-leucine, L-ornithine, L-phenylalanine, L-proline, Lserine, L-tryptophan, 3-hydroxybenzoate, 4-hydroxybenzoate and phenylacetate. The DNA G $+\mathrm{C}$ content is $59 \mathrm{~mol} \%$.

The type strain, CCUG $47242^{\mathrm{T}}\left(=\mathrm{DSM} 17683^{\mathrm{T}}=\mathrm{CIP}\right.$ $108492^{\mathrm{T}}$ ), was isolated from a sample of industrial starch production in Sweden.

\section{Description of Cohnella hongkongensis sp. nov.}

Cohnella hongkongensis (hong.kong.en'sis. N.L. fem. adj. hongkongensis pertaining to Hong Kong).

The name 'Paenibacillus hongkongensis' has been used for this organism, but it has not been validly published and cannot be formally cited as a synonym.

In addition to the description given by Teng et al. (2003), the type strain utilizes several sole carbon sources after 7 days of incubation: $\mathrm{N}$-acetyl-D-galactosamine, $\mathrm{N}$-acetylD-glucosamine, arbutin, L-arabinose (weakly), D-cellobiose, D-fructose, D-galactose, gluconate, D-glucose, D-maltose, D-mannose, $\alpha$-D-melibiose, L-rhamnose and D-ribose. The following carbon sources are not utilized: sucrose, salicin, D-trehalose, D-xylose, adonitol, i-inositol, maltitol, Dmannitol, D-sorbitol, putrescine, acetate, propionate, cisaconitate, trans-aconitate, adipate, 4 -aminobutyrate, azelate, citrate, fumarate, glutarate, DL-3-hydroxybutyrate, itaconate, DL-lactate, L-malate, mesaconate, oxoglutarate, pyruvate, suberate, L-alanine, $\beta$-alanine, L-aspartate, L-histidine, L-leucine, L-ornithine, L-phenylalanine, L-proline, L-serine, L-tryptophan, 3-hydroxybenzoate, 4-hydroxybenzoate and phenylacetate. The fatty acid profile of the type strain contains iso $\mathrm{C} 16: 0(11.9 \%)$, anteiso $\mathrm{C} 15: 0(31 \cdot 2 \%)$, 
anteiso C17 : 0 (2.6\%), C16:0 (25.3\%), iso C15:0 (8.1\%), anteiso $\mathrm{C} 13: 0(0 \cdot 8 \%)$, iso $\mathrm{C} 14: 0(2 \cdot 3 \%), \mathrm{C} 15: 0(8 \cdot 0 \%)$, C16: $1 \omega 11 c(0 \cdot 9 \%)$, iso C17: $0(1 \cdot 9 \%), \mathrm{C} 14: 0(5 \cdot 0 \%)$ and C17:0 $(1 \cdot 2 \%)$. The DNA G $+\mathrm{C}$ content is $60 \cdot 9 \mathrm{~mol} \%$ (method according to Peña et al., 2005).

The type strain is $\mathrm{HKU}^{\mathrm{T}}\left(=\mathrm{DSM} 17642^{\mathrm{T}}=\mathrm{CIP} 107898^{\mathrm{T}}=\right.$ CCUG $49571^{\mathrm{T}}$ ).

\section{References}

Aguilera, M., Monteoliva-Sánchez, M., Suárez, A., Guerra, V., Lizama, C., Bennasar, A. \& Ramos-Cormenzana, A. (2001). Paenibacillus jamilae sp. nov., an exopolysaccharide-producing bacterium able to grow in olive-mill wastewater. Int J Syst Evol Microbiol 51, 1687-1692.

Ash, C., Farrow, J. A. E., Wallbanks, S. \& Collins, M. D. (1991). Phylogenetic heterogeneity of the genus Bacillus revealed by comparative analysis of small-subunit-ribosomal RNA sequences. Lett Appl Microbiol 13, 202-206.

Ash, C., Priest, F. G. \& Collins, M. D. (1993). Molecular identification of rRNA group 3 bacilli (Ash, Farrow, Wallbanks and Collins) using a PCR probe test. Proposal for the creation of a new genus Paenibacillus. Antonie van Leeuwenhoek 64, 253-260.

Ash, C., Priest, F. G. \& Collins, M. D. (1994). Paenibacillus gen. nov. In Validation of the Publication of New Names and New Combinations Previously Effectively Published Outside the IJSB, List no. 51. Int J Syst Bacteriol 44, 852.

Berge, O., Guinebretière, M.-H., Achouak, W., Normand, P. \& Heulin, T. (2002). Paenibacillus graminis sp. nov. and Paenibacillus odorifer sp. nov., isolated from plant roots, soil and food. Int J Syst Evol Microbiol 52, 607-616.

Bosshard, P. P., Zbinden, R. \& Altwegg, M. (2002). Paenibacillus turicensis sp. nov., a novel bacterium harbouring heterogeneities between 16S rRNA genes. Int J Syst Evol Microbiol 52, 2241-2249.

Elo, S., Suominen, I., Kämpfer, P., Juhanoja, J., Salkinoja-Salonen, M. \& Haahtela, K. (2001). Paenibacillus borealis sp. nov., a nitrogenfixing species isolated from spruce forest humus in Finland. Int J Syst Evol Microbiol 51, 535-545.

Fischer, W. \& Arneth-Seifert, D. (1998). D-Alanylcardiolipin, a major component of the unique lipid pattern of Vagococcus fluvialis. J Bacteriol 180, 2950-2957.

Fischer, W. \& Leopold, K. (1999). Polar lipids of four listeria species containing L-lysylcardiolipin, a novel lipid structure, and other unique phospholipids. Int J Syst Bacteriol 49, 653-662.

Genersch, E., Forsgren, E., Pentikäinen, J., Ashiralieva, A., Rauch, S., Kilwinski, J. \& Fries, I. (2006). Reclassification of Paenibacillus larvae subsp. pulvifaciens and Paenibacillus larvae subsp. larvae as Paenibacillus larvae without subspecies differentiation. Int J Syst Evol Microbiol 56, 501-511.

Gerhardt, P., Murray, R. G. E., Wood, W. A. \& Krieg, N. R. (editors) (1994). Methods for General and Molecular Bacteriology. Washington, DC: American Society for Microbiology.

Gould, R. M. \& Lennarz, W. J. (1967). Biosynthesis of aminoacyl derivatives of phosphatidylglycerol. Biochem Biophys Res Commun 26, 510-515.

Gould, R. M. \& Lennarz, W. J. (1970). Metabolism of phosphatidylglycerol and lysyl-phosphatidylglycerol in Staphylococcus aureus. J Bacteriol 104, 1135-1144.

Heyrman, J., Logan, N.A., Rodríguez-Díaz, M., Scheldeman, P., Lebbe, L., Swings, J., Heyndrickx, M. \& De Vos, P. (2005). Study of mural painting isolates, leading to the transfer of 'Bacillus maroccanus' and 'Bacillus carotarum' to Bacillus simplex, emended description of Bacillus simplex, re-examination of the strains previously attributed to 'Bacillus macroides' and description of Bacillus muralis sp. nov. Int J Syst Evol Microbiol 55, 119-131.

lida, K., Ueda, Y., Kawamura, Y., Ezaki, T., Takade, A., Yoshida, S. \& Amako, K. (2005). Paenibacillus motobuensis sp. nov., isolated from a composting machine utilizing soil from Motobu-town, Okinawa, Japan. Int J Syst Evol Microbiol 55, 1811-1816.

Kämpfer, P. (2002). Whole-cell fatty acid analysis in the systematics of Bacillus and related genera. In Applications and Systematics of Bacillus and Relatives, pp. 271-299. Edited by R. Berkeley, M. Heyndrickx, N. Logan \& P. De Vos. Oxford: Blackwell Science.

Kämpfer, P. \& Kroppenstedt, R. M. (1996). Numerical analysis of fatty acid patterns of coryneform bacteria and related taxa. Can J Microbiol 42, 989-1005.

Kämpfer, P., Steiof, M. \& Dott, W. (1991). Microbiological characterisation of a fuel-oil contaminated site including numerical identification of heterotrophic water and soil bacteria. Microb Ecol 21, 227-251.

Kämpfer, P., Dreyer, U., Neef, A., Dott, W. \& Busse, H.-J. (2003). Chryseobacterium defluvii sp. nov., isolated from wastewater. Int J Syst Evol Microbiol 53, 93-97.

Kim, D.-S., Bae, C.-Y., Jeon, J.-J., Chun, S.-J., Oh, H. W., Hong, S. G., Baek, K.-S., Moon, E. Y. \& Bae, K. S. (2004). Paenibacillus elgii sp. nov., with broad antimicrobial activity. Int J Syst Evol Microbiol 54, 2031-2035.

Kumar, S., Tamura, K., Jakobsen, I. B. \& Nei, M. (2001). MEGA2: molecular evolutionary genetics analysis software. Bioinformatics 17, 1244-1245.

Lennarz, W. J., Nesbitt, J. A., III \& Reiss, J. (1966). The participation of sRNA in the enzymatic synthesis of o-L-lysyl phosphatidylglycerol in Staphylococcus aureus. Proc Natl Acad Sci U S A 55, 934-941.

Meehan, C., Bjourson, A. J. \& McMullan, G. (2001). Paenibacillus azoreducens sp. nov., a synthetic azo dye decolorizing bacterium from industrial wastewater. Int J Syst Evol Microbiol 51, 1681-1685.

Minnikin, D. E. \& Goodfellow, M. (1981). Lipids in the classification of Bacillus and related taxa. In The Aerobic Endospore-Forming Bacteria, pp. 59-90. Special Publication of the Society for General Microbiology, no. 4. Edited by R. C. W. Berkeley \& M. Goodfellow. London: Academic Press.

Montes, J. Ma, Mercadé, E., Bozal, N. \& Guinea, J. (2004). Paenibacillus antarcticus sp. nov., a novel psychrotolerant organism from the Antarctic environment. Int J Syst Evol Microbiol 54, 1521-1526.

Nahaie, M. R., Goodfellow, M., Minnikin, D. E. \& Hájek, V. (1984). Polar lipid and isoprenoid quinone composition in the classification of Staphylococcus. J Gen Microbiol 130, 2427-2437.

Oku, Y., Kurokawa, K., Ichihashi, N. \& Sekimizu, K. (2004). Characterization of the Staphylococcus aureus mprF gene, involved in lysinylation of phosphatidylglycerol. Microbiology 150, 45-51.

O'Leary, W. M. \& Wilkinson, S. G. (1988). Gram-positive bacteria. In Microbial Lipids, vol. 1, pp.117-201. Edited by C. Ratledge \& S. G. Wilkinson. London: Academic Press.

Peña, A., Valens, M., Santos, F., Buczolits, S., Antón, J., Kämpfer, P., Busse, H.-J., Amann, R. \& Rosselló-Mora, R. (2005). Intraspecific comparative analysis of the species Salinibacter ruber. Extremophiles 9, 151-161.

Rivas, R., Mateos, P. F., Martínez-Molina, E. \& Velázquez, E. (2005a). Paenibacillus xylanilyticus sp. nov., an airborne xylanolytic bacterium. Int J Syst Evol Microbiol 55, 405-408.

Rivas, R., Mateos, P. F., Martínez-Molina, E. \& Velázquez, E. (2005b). Paenibacillus phyllosphaerae sp. nov., a xylanolytic bacterium isolated from the phyllosphere of Phoenix dactylifera. Int J Syst Evol Microbiol 55, 743-746. 
Rodríguez-Díaz, M., Lebbe, L., Rodelas, B., Heyrman, J., De Vos, P. \& Logan, N. A. (2005). Paenibacillus wynnii sp. nov., a novel species harbouring the nifH gene, isolated from Alexander Island, Antarctica. Int J Syst Evol Microbiol 55, 2093-2099.

Saha, P., Mondal, A. K., Mayilraj, S., Krishnamurthi, S., Bhattacharya, A. \& Chakrabarti, T. (2005). Paenibacillus assamensis sp. nov., a novel bacterium isolated from a warm spring in Assam, India. Int J Syst Evol Microbiol 55, 2577-2581.

Sánchez, M. M., Fritze, D., Blanco, A., Spröer, C., Tindall, B. J., Schumann, P., Kroppenstedt, R. M., Diaz, P. \& Pastor, F. I. J. (2005). Paenibacillus barcinonensis sp. nov., a xylanase-producing bacterium isolated from a rice field in the Ebro River delta. Int J Syst Evol Microbiol 55, 935-939.

Shida, O., Takagi, H., Kadowaki, K., Nakamura, L. K. \& Komagata, K. (1997). Transfer of Bacillus alginolyticus, Bacillus chondroitinus, Bacillus curdlanolyticus, Bacillus glucanolyticus, Bacillus kobensis, and Bacillus thiaminolyticus to the genus Paenibacillus and emended description of the genus Paenibacillus. Int J Syst Bacteriol 47, 289-298.

Šmerda, J., Sedláček, I., Páčová, Z., Durnová, E., Smíšková, A. \& Havel, L. (2005). Paenibacillus mendelii sp. nov., from surfacesterilized seeds of Pisum sativum L. Int J Syst Evol Microbiol 55, 2351-2354.

Stackebrandt, E. \& Swiderski, J. (2002). From phylogeny to systematics: the dissection of the genus Bacillus. In Applications and Systematics of Bacillus and Relatives, pp. 8-22. Edited by R. Berkeley, M. Heyndrickx, N. Logan \& P. De Vos. Oxford: Blackwell Science.

Takeda, M., Suzuki, I. \& Koizumi, J. (2005). Paenibacillus hodogayensis sp. nov., capable of degrading the polysaccharide produced by Sphaerotilus natans. Int J Syst Evol Microbiol 55, 737-741.
Teng, J. L., Woo, P. C., Leung, K. W., Lau, S. K., Wong, M. K. \& Yuen, K. Y. (2003). Pseudobacteraemia in a patient with neutropenic fever caused by a novel paenibacillus species: Paenibacillus hongkongensis sp. nov. Mol Pathol 56, 29-35.

Thompson, J. D., Gibson, T. J., Plewniak, F., Jeanmougin, F. \& Higgins, D. G. (1997). The CLUSTAL_X windows interface: flexible strategies for multiple sequence alignment aided by quality analysis tools. Nucleic Acids Res 25, 4876-4882.

Tindall, B. J. (1990). Lipid composition of Halobacterium lacusprofundi. FEMS Microbiol Lett 66, 199-202.

Touzel, J. P. O’Donohue, M., Debeire, P., Samain, E. \& Breton, C. (2000). Thermobacillus xylanilyticus gen. nov., sp. nov., a new aerobic thermophilic xylan-degrading bacterium isolated from farm soil. Int J Syst Evol Microbiol 50, 315-320.

von der Weid, I., Duarte, G. F., van Elsas, J. D. \& Seldin, L. (2002). Paenibacillus brasilensis sp. nov., a novel nitrogen-fixing species isolated from the maize rhizosphere in Brazil. Int $J$ Syst Evol Microbiol 52, 2147-2153.

Wayne, L. G., Brenner, D. J., Colwell, R. R. \& 9 other authors (1987) International Committee on Systematic Bacteriology. Report of the ad hoc committee on the reconciliation of approaches to bacterial systematics. Int J Syst Bacteriol 37, 463-464.

Yoon, J.-H., Oh, H.-M., Yoon, B.-D., Kang, K. H. \& Park, Y.-H. (2003). Paenibacillus kribbensis sp. nov. and Paenibacillus terrae sp. nov., bioflocculants for efficient harvesting of algal cells. Int J Syst Evol Microbiol 53, 295-301.

Yoon, J.-H., Kang, S.-J., Yeo, S.-H. \& Oh, T.-K. (2005). Paenibacillus alkaliterrae sp. nov., isolated from an alkaline soil in Korea. Int J Syst Evol Microbiol 55, 2339-2344. 